DOI: 10.20472/IAC.2017.33.041

\author{
JAE-MIN LEE
}

Korea Institute of S\&T Evaluation and Planning, Korea, Republic of

\title{
SUSTAINABILITY OF SPACE PROGRAM IN SOUTH KOREA: CURRENT STATUS AND FUTURE DIRECTIONS
}

\begin{abstract}
:
Since 1992 when the Korea's first satellite KITSAT-1 was launched, the government of Korea has poured many efforts and $R \& D$ resources in securing space technologies so as to join one of world leading countries in space development. As a result, Korea has own technologies that enable observing earth and exploring space in various orbits, colours, and spatial resolutions. Also, it is expected that the Korea's space launch vehicle(KSLV), which will be launched in 2019 for the first time, will be the most important achievement in Korea's space history. Currently, the growth in national $R \& D$ expenditure for space program is, however, challenged by issues that arise due to changing domestic and foreign situations, and thus sustainability of space program in Korea becomes more challenging than any other time. The strategy for the government-leading space development lasting for more than past 25 years is also needed to be reconsidered. Here, I present the current status of Korea's space program, which covers a short history and a diagnosis of space development in Korea. I also discuss the future directions of Korea's space program that suggest possible solutions for maintaining its sustainability.
\end{abstract}

\section{Keywords:}

space development in korea, sustainability, national $R \& D$ in Korea 